\title{
Technical Efficiency and Agricultural Sustainability of Jambi's Corn Production
}

\author{
Edison Edison ${ }^{1, *}$ Rosyani Rosyani ${ }^{2}$
}

\author{
${ }^{1,2}$ Dept. of Agribusiness, University of Jambi, Jambi 36361, Indonesia \\ *Corresponding author. Email: ediedison950@yahoo.co.id
}

\begin{abstract}
Jambi is a unique province in Indonesia that has a diverse climate and natural resources to improve the yield of many commodities like corn. In terms of improving domestic corn and decreasing production loss, more producers apply high portions of un-organic fertilizers, and pesticides, with not thinking about the impact of temporary and long-time environmental problems. The research aim was to analyze technical efficiency and sustainable corn production through sustainable agriculture in Jambi province. Technical efficiency and agricultural sustainability model applied using a stochastic production frontier. The research location was chosen in peat land, and also data were collected through interviewing 120 corn producers in Jambi that chosen by systematic random sampling. The research finding of the analysis showed mean technical efficiency scores of about $74 \%$, meaning that the agricultural production in Jambi produces 74 percent of the potential yield given the technical efficiency existing in the research area. Agricultural sustainability results also give a good implication on corn production. This means that the technical efficiency and agriculture sustainability of a rather sustainable region in corn production had impacted properly.
\end{abstract}

Keywords: Technical Efficiency, Corn Production, And Sustainable Agriculture.

\section{INTRODUCTION}

Agriculture has been known over the years to play a crucial role in economic growth of developing countries. Important agricultural sectors to the growth of under developed or developing countries are still debatable. In Indonesia, agriculture has consistently played an important role on the growth food sector, input for industries sector, labor force, and National earnings, that are sources for Growth Domestic Product (GDP) [1].

Agriculture production in Indonesia is also plagued with small productivity compared to non-agricultural production in other countries or to agricultural production in developed countries. Reasons for small agricultural productivity likely include limited knowledge about methods to enhance productivity and best productive technologies, shortage or lack of link to best productive varieties and inputs productivity-improvement, access limitation of liquidity and access limitation to credit, and also reluctance to invest in value productivity improvement value because of risk factor poor product prices, and bad market available compared to the risk aversion of poor farmers [2].
The sector of agriculture becomes important to get food security and also economic growth, representing about $13.53 \%$ of Indonesia's GDP and $38.3 \%$ of the active labor force. Globally, agriculture's share in GDP is only $13.45 \%$. Agricultural exports come up about USD 370 million, or $24.35 \%$ of all products and services exported from Indonesia. However, the rest of sectors are constrained by low productivity and major environmental problems. A $12 \%$ decline in rainfall over the last 10 years has had serious problems for dry land locations. Perhectare yields for most crops are among the lowest in the world, only increasing by an average of $29 \%$ between 1990 and 2015, and accounting for just $28 \%$ of the growth in agricultural and food production [3].

Although Indonesia has a lot of source of water, including rivers and river basins, access to those source of water is still having constraint. Agriculture has depending on rain-fed and also mostly small farmers with bad access to services on agricultural technologies, information, and finance. Therefore, Indonesian agricultural sector is mostly vulnerable to weather variability, degradation of soil fertility, and infestations of pests and diseases [4]. 
These factors have led to inefficiency in agricultural production in the region [3]. Statement of research problem long-term economic development is brought about by sustainable economic growth, which is also predisposed by agricultural development. Agricultural development crucially depends on the efficient and most productive use of scarce production resources. Agricultural production is plagued with the scarcity of resources and hence resource use efficiency is critical to improved agricultural practices [5].

The technical efficiency of agricultural production means to be able to create a maximazation output as best availability input group. To evaluate technical efficiency of firm, there needs technical efficiency components via transformation input to output $[6,7]$. The traditional approaches to estimate technological efficiency consider that all production variables are the same and have a connection to similar technological production $[8,9]$.

Based on that characteristics, a production frontier is mostly analyzed in terms of assessing technical efficiency analysis of set of production. On the other hand, some empirical components are available in which unit of production in evaluation unit works in rather not the same production environments, which means they have a link to other production possibilities components. Condition technological variation reflects not similar in the social, physical, and economic variables of the environments where production takes place [7].

If variables are facing alternatives from varied production possibilities group after that the usual consideration of evaluating mono technology frontier may find technical efficiency and productivity estimation may not exactly measurement ability of unit of production to change inputs into outputs. The new metafrontier consideration of $[10,11]$ considers to assess and evaluate unit of efficiency of yield that have link to varied production possibilities groups. The model has been applied mostly in reference to investigate technical efficiency of farming sets in industries in varies agriculture (e.g., [12, 13]. The concept involves evaluating varied frontiers for varied groups of units production, finally, able to assess the gap between these group frontier and meta-frontier.

Using the meta frontier approach is more effective in comparing relative technical efficiency levels across regions and assessing the potency to increase regions efficiency $[14,15]$. The advantage of meta frontier is attractive theoretically because of the simple hypothesis based that all producers in different regions have potential access to the same technology [7]. It is in light of the above that the study seeks evaluate technical efficiency and relative technology gaps across the selected regions [16].

\section{METHODS}

The data was collected from household survey and carried out in Muaro Jambi of Jambi. The survey questionnaire contains the necessary information needed to identify household and institutional characteristics, as well as inputs and outputs in corn production. The study is based on primary data and secondary data sourced on the Indonesian Food and Agricultural Department. Data on Agricultural production indices of Indonesian for 35 years (1984-2018) were randomly selected for this study. Primary data used in research are 120 corn producers. The variables considered in the models were corn output (corn production) while the inputs considered include: land [agricultural] (Ha); labor [economically active persons in agriculture]; Fertilizer[urea] (tons); Fertilizer[NPK] (tons) and Seed (tons). The empirical application has three steps. First is the estimation of one Stochastic Production Function (SPF). The second step involved the estimation of one SPF for the whole data set. In the final step, the calculation of the MF using the estimates from individual SPF's was performed.

\subsection{The Empirical Model of the Stochastic Frontier Production Function}

To estimate empirical model, the study applies CobbDouglas production function. According to [17], the function is applied to see the input-output relationship in the Stochastic Frontier function equation and is carried out in 2 stages, first using the Ordinary Least Square (OLS) method, which is used to estimate the coefficient of production input $\beta$. The second is done by applying the Maximum Likelihood Estimation (MLE) method to estimate all production parameters $\beta \mathrm{m}$, intercept $\beta 0$, as well as factor variants of the two error components vi and ui [18]:

$$
\mathrm{Y}=\beta_{0} \mathrm{X}_{1}^{\beta 1} \mathrm{X}_{2}^{\beta 2} \mathrm{X}_{3}^{\beta 3} \mathrm{X}_{4}^{\beta 4} \mathrm{X}_{5}^{\beta 5} \mathrm{X}_{6}^{\beta 6} e^{v i-u i} \ldots
$$

Analytical Techniques First, the parameters of the stochastic frontiers were estimated using the trans log (TL) specification:

$$
\begin{aligned}
& \log Y=\beta_{0}+\beta_{1} \log X_{1}+\beta_{2} \log X_{2}+\beta_{3} \log X_{3}+ \\
& \beta_{4} \log X_{4}+\beta_{5} \log X_{5}+\beta_{6} \log X_{6}+\left(v_{i}-u_{i}\right) \ldots(2)
\end{aligned}
$$

Both indices $\mathrm{j}$ and $\mathrm{i}$ represents the input $\mathrm{j}$ used by farmer i, respectively and all variables use natural logarithm. Six input weas included in the model. Most of these variables have been commonly used in estimating agricultural production frontiers [19]. ' $\mathrm{Y}$ ' represents corn measured as the number of production; ' $\mathrm{X} 1$ ' denotes the total productive land area in hectares. ' $\mathrm{X} 2$ 'represents seed in tonnes. ' $\mathrm{X} 3$ ' is the fertilizer of Urea measured in tonnes; ' $\mathrm{X} 4$ ' stands for fertilizer[urea] measured in tonnes ' $\mathrm{X} 5$ ' stands for fertilizer[NPK] measured in tonnes and ' $\mathrm{X} 6$ ' stands for the amount of labor, which includes economically active persons in agriculture 
measured in ' 000 ; v's is assumed to be independently and distributed identically $(0$,$) two-sided random errors,$ independently of u's. Finally, the results from the trans $\log$ specifications are used to analyze meta frontier parameters by solving trans log model Eq. 2 .

\section{RESULTS}

\subsection{Variable descriptions and summary statistics}

Research finding concerning variables that affect the technical efficiency of corn production was exciting and also magnificent. Finding from Table 1 explains description and summary statistics for variables including variables, description, averages, standard deviations, and also values of minimum and maximum. These showed that mean output per hectare is around 11 tons, mean land used 2.27 ha, using 20 hours of labor, 101 kilograms of urea fertilizer, 75 kilograms NPK fertilizer, and 2.8 liters pesticide.

Table 1. Variable descriptions and summary statistics.

\begin{tabular}{|l|l|c|c|c|c|}
\hline Variable & Description & Mean & Std.Dev. & Min & Max \\
\hline Output & $\begin{array}{l}\text { Total yield per hectare } \\
\text { Total land used in hectare }\end{array}$ & 10.44 & 1.09 & 3.5 & 18 \\
\hline Ln(seed) & $\begin{array}{l}\text { Quantity of seed applied by hectare } \\
\text { in kilograms. }\end{array}$ & 34.16 & 2.89 & 10.00 & 16.00 \\
\hline Ln(fertilizer of urea) & $\begin{array}{l}\text { Quantity of fertilizer of urea applied } \\
\text { by hectare in kilograms. }\end{array}$ & 101.27 & 54.92 & 77 & 150 \\
\hline Ln(fertilizer of NPK) & $\begin{array}{l}\text { Quantity of fertilizer of NPK } \\
\text { applied by hectare in kilograms. }\end{array}$ & 75.22 & 73.04 & 50 & 100 \\
\hline Ln (pesticide) & $\begin{array}{l}\text { Quantity of pesticide applied by } \\
\text { hectare in litre. }\end{array}$ & 2.80 & 1.97 & 1.20 & 4.00 \\
\hline Ln (labour) & $\begin{array}{l}\text { Total of man-hours } \\
\text { per day. }\end{array}$ & 19.8 & 1.83 & 1 & 6 \\
\hline
\end{tabular}

\subsection{Restriction Test on Parameter Production Function}

This study examines the meta production function to the yield inherent in the production function. Parameters of the expected production function using ordinary least squares. To test the significance of each parameter, the null hypothesis can be expressed as $\mathrm{H} 0: \beta 1=\beta 2=\ldots=$ $\beta n=0$. The estimation results of optimal corn production parameters for yield can be seen in Table 2. The analysis shows that the hypothesis $\beta 1=\beta 2=\ldots=\beta \mathrm{n}=0$ can be rejected. The approximate elasticity of the production function for corn is listed in Table 2, the adjusted Rsquared for the OLS estimate is 0.816 , and the F-statistic $(6,114)$ is 8.26 , which is significantly greater than the Ftable $(6,114)$.,$\alpha=0.01)=2.96$. This means that at least one of the parameters is not equal to zero. From Table 2. It can also be seen that the parameters of some explanatory variables are significantly different from zero.

Table 2. Restriction Test on Parameters $\beta$ Production Function

\begin{tabular}{|c|c|c|c|}
\hline Variable & Lagrange ( $\square$ ) & Multiplier (t) & $\mathrm{x}^{2 \text { test }}$ \\
\hline Land & $0.201 \quad(0,139)$ & 1.446 & \multirow{8}{*}{9,372} \\
\hline Seed & $(0,011)$ & $7.545 * * *$ & \\
\hline Fertilizer (Urea) & (0.068) & $3.206 * *$ & \\
\hline Fertilizer (NPK) & $(0.056)$ & $3.464 * *$ & \\
\hline Pesticide & $0.153 \quad(0.066)$ & 2.318 & \\
\hline Labour & $0.138 \quad(0.043)$ & $3.209 * *$ & \\
\hline Adj. R-squared & 0.896 & & \\
\hline F-statistic & 8.26 & & \\
\hline
\end{tabular}

\subsection{Maximum Likelihood Estimation of the Stochastic Frontier and Meta Frontier}

An Likelihood Ratio test to examine the null hypothesis that research region shares the same technology was performed. If the research region shares same production frontier (i.e., no significant difference between research site frontiers), then there would be no reason for estimating data meta-frontier production model. 
Table 3. MLE Estimates of the Stochastic Frontier and Meta Frontier

\begin{tabular}{|l|c|c|c|c|}
\hline \multirow{2}{*}{ Variable } & \multicolumn{2}{|c|}{ Stochastic Frontier } & \multicolumn{2}{c|}{ Meta Frontier } \\
\cline { 2 - 5 } & Coefficient & Std. Error & Coefficient & Std. Error \\
\hline Cosntant & 6.628 & 1.295 & 4.643 & 3.249 \\
\hline Ln $X_{1}$ & 1.470 & 0.316 & 1.092 & 0.111 \\
\hline Ln $X_{2}$ & 0.837 & 0.124 & 0.627 & 0.287 \\
\hline Ln $X_{3}$ & 1.151 & 0.144 & 0.925 & 0.146 \\
\hline Ln X 4 & 1.030 & 0.011 & 1.142 & 0.223 \\
\hline Ln $X_{5}$ & 0.046 & 0.026 & 0.270 & 0.071 \\
\hline Ln $X_{6}$ & 0.234 & 0.016 & 0.324 & 0.093 \\
\hline Log likelihood & 78.362 & & & \\
\hline LR test & 18.13 & & & \\
Mean efficiency & 0.74 & & & \\
\hline
\end{tabular}

\section{DISCUSSION}

An important condition for reducing the production function used is that the farmer maximizes the short term of production. The validity of this assumption can be tested directly by testing whether the parameter is derived from the demand factor equation simultaneously [20]. If the parameter $\square$ derived from these equations is not significantly different, then the average sample farmer maximizes the short-term production, given the availability of technology and resources. Because it is very feasible to estimate simultaneously the production equation to avoid the bias problem of the simultaneous equation, [20] used the $\mathrm{P}$ statistics to test the null hypothesis which $\square \mathrm{i}$ is not significantly different, when $\square \mathrm{i}$ is derived from two separate and combined sets of equations. Lagrange multipliers were not significantly different from zero, neither was the X2 test (Table 2). So the hypothesis that the peat land corn farmer in the study area maximizes production cannot be rejected.

Table 2 shows the value of Adj $\mathrm{R} 2=0.896$, this means that 89.6 percentage of the variation in dependent variable can be explained simultaneously by independent variables such as land area, seeds, fertilizers, pesticides, and labor, while the remaining 10.4 percent is influenced by other factors outside the model. The effect of using production factors simultaneously on the production of maize can be determined using the $\mathrm{F}$ test, and the analysis results obtained by $\mathrm{F}$ statistics of 8.26 with a probability of $0.0000<(0.01)$ shows that the results have a very significant effect, meaning that the independent variables contained in the model simultaneously had a very significant effect on corn production. The value of $\square \square \mathrm{i}$ $=0.987<1$, this means that the simultaneous use of production factors in area II, which means that each addition to the same input proportion will result in a decreasing increase in output, in other words, corn farming is in the production stage of decreasing return to scale.

This section describes results of the estimation of corn production frontiers and associated technical efficiency (TE) measures. First, the Stochastic
Production Function results and specification tests are analyzed. Second, TE measures are discussed and then the TE measures with respect to the meta frontier are examined. Summary statistics of the variables for agricultural production differences in economic development could be responsible for differences in information transmission, technology adoption, and even institutions associated with agricultural production. In other words, technology diffusion may follow a geographic connecting pattern [8]. The variation in the economic development is the motivation for estimating the differences in their agricultural technologies, that is, whether they have access to different production possibility sets which should be considered when measuring production efficiencies The summary statistics in Table 3 display the mean cumulative variables identified in research region in the research period.

The analysis found that the value of the LR statistic is 48.13 which means highly significant and implying that the null hypothesis is rejected. The founding suggests that the region stochastic frontiers for agricultural production in Jambi are not the same, meaning that production structure and technology adoption are different in the research site. Therefore, the meta-frontier technique is the appropriate estimation approach for this study, and that any efficiency in the research region should be undertaken with respect to the meta-frontier.

\section{CONCLUSIONS}

This study applied stochastic production frontier function technique to analyze technology gaps and technical efficiency in corn agricultural production in Muaro Jambi. The methodology enables the estimation of technology involving the (regional) stochastic production frontier. Stochastic production frontier models were estimated for these regions to obtain alternative estimates for their technical efficiency. The findings of the analysis showed technical efficiency scores with an average of about $74 \%$, meaning that the agricultural production in Jambi produces 74 percent of the potential output given the technical efficiency 
available in the research location. The research shows it able to clarify the characteristics of the exploration research region that needs to improve agricultural production. This means that the technical efficiency and agriculture sustainability of a relatively sustainable region in corn production had impacted properly Therefore, producers in the research area can minimize the gap between technology and sustainable agriculture levels through applying technology that is suitable for agricultural sustainability.

\section{ACKNOWLEDGMENTS}

This research was funded by University Fund Grand with contract number: 1000/UN21/AM/2020. Acknowledgments of gratitude were also to the research team who contributed so much during data collection. The researcher also thanked the respondents for their cooperation in this study.

\section{REFERENCES}

[1] Edison and I Wahyuni 2020 Acreage Response Under Price Policy Program on Agricultural Corn Production. International Journal of Scientific and Technology Research 1(1):25-32.

[2] A. Henningsen, Daniel F M, Anwar S A, Joseph, A K and G C Tomasz 2015 A Meta-Frontier Approach for Causal Inference in Productivity Analysis: The Effect of Contract Farming on Sunflower Productivity in Tanzania. Selected paper at Agricultural \& Applied Economics Association and Western Agricultural Economics Association Annual Meeting, San Francisco, CA, July 26-28.

[3] J. Blanke. 2017 Realising West Africa's True Agricultural Potential. Africa Development Bank. https://www.scibd.com/document/afdb-2017

[4] R. Asmara, Fahriyah and F Hanani. 2017 Technical, Cost and Allocative Efficiency of Rice, Corn, and Soybean Farming in Indonesia : Data Envelopment Analysis Approach. Agricultural Socio-Economics Journal 17(2):76-80.

[5] R. Adeyemo, Oke J T O and A A Akinola 2010 Economic Efficiency of Small Scale Farmers in Ogun State, Nigeria. Tropicultura 28(2): 84-88.

[6] J.N. Binam, Gockowski J and G B Nkamleu 2008 Technical Efficiency and Productivity Potential of Cocoa Farmers in West Africa Countries. The Developing Economics 3: 242-263.

[7] C.J. O'Donnell, Rao D S P and G E Battese 2008 Meta-frontier frameworks for the study of firm-level efficiencies and technology ratios. Empirical Economics, 34(2): 231-255.
[8] Z. Chen and S Song 2008 Efficiency and Technology Gap in China's Agriculture: A Regional Metafrontier analysis. China Economic Review 19(2):287-296.

[9] H. Boshrabadi, Villano R and E Fleming 2008 Technical Efficiency and Environmental Technological Gaps in Wheat Production in Kerman Province of Iran. Agricultural Economics 38(1):6776.

[10] G.E. Battese and D S P Rao 2002 Technology Gap, Efficiency, and a Stochastic Meta-frontier Function. International Journal of Business and Economics, $1(2): 87-93$.

[11] G.E. Battese, Rao D S P and C O’Donnell 2004 A Meta-frontier Production Function for Estimation of Technical Efficiencies and Technology Gaps for Firms Operating under Different Technologies. Journal of Productivity Analysis, 21(1):91-103.

[12] J.D. Otieno, Hubbard L and E Ruto 2014 Assessment of Technical Efficiency and Its Determinants in Beef Cattle Production in Kenya. Journal of Development and Agricultural Economics 6(6): 267-278.

[13] A. Chebil1, Abdelaziz A H, Alawia O H, Ishtiag A, Izzat T, Solomon, A and Y Ouambi 2016 Metafrontier Analysis of Technical Efficiency of Wheat Farms in Sudan. Journal of Agricultural Science 8 (2): 179-186.

[14] O. Isaac. 2011 Technical Efficiency of Maize Poduction in Oyo State. Journal of Economics and International Finance. 3(4): 211-216.

[15] J.A. Onumah, Onumah E E, Al-Hassan R M and B Brumme 2013 Meta-frontier Analysis of Organic and Conventional Cocoa Production in Ghana. Agricicultural Economics Czech 59(6): 271-280.

[16] B.J. Nyemeck, Gockowski J and G B Nkamleu 2008 Technical Efficiency and Productivity Potential of Cocoa Farmers in West African Countries: A Meta Frontier Approach. The Developing Economies 46(3): 242-63.

[17] T. Coelli, Rao D S P and G E Battese 2005 An Introduction to Efficiency and Productivity Analysis, second edition, Kluwer Academic Publishers, Boston.

[18] W.H. Greene. 2003 Econometric Analysis, fifth edition, ISBN: 0-13-110849-2, New York: Prentice Hall.

[19] X. Wang and S Rungsuriyawiboon 2010 Agricultural Efficiency, Technical Change and Productivity in China, Post-Communist Economies 22(2): 207-227

[20]. Edison 2014 The Responsiveness of Rice Area to Price and Production Cost in Jambi. International Journal of Agricultural System 2(2):133-139 